\title{
Habilidades sociocomunicativas de bebês no primeiro ano de vida: um estudo longitudinal ${ }^{1}$
}

\author{
Fabíola de Sousa Braz Aquino² \\ Nádia Maria Ribeiro Salomão \\ Universidade Federal da Paraíba, João Pessoa-PB, Brasil
}

\begin{abstract}
Resumo: Este artigo objetiva identificar as principais habilidades sociocomunicativas evidenciadas por bebês em três momentos do primeiro ano de vida e suas diferentes configurações em cada idade. Destaca-se a ideia de que compreender a dimensão sociocognitiva e comunicativa infantil é fundamental para um entendimento mais aprofundado da gênese do desenvolvimento humano e da linguagem. Participaram da pesquisa seis díades mãe-bebê nas idades de seis, nove e doze meses, observadas em suas residências, em situação de brincadeira livre, durante 40 minutos em cada idade. Os resultados das análises demonstraram que as habilidades sociocomunicativas dos bebês estudados foram se reconfigurando em cada idade subsequente, permitindo identificar, principalmente aos 12 meses, a existência de habilidades comunicativas intencionais. Os dados obtidos neste estudo contribuem para maior compreensão acerca da cognição social infantil no primeiro ano de vida e suas relações com a aquisição da linguagem.
\end{abstract}

Palavras-chave: cognição social, intencionalidade, relações mãe-criança.

\section{The socio-communicative abilities of infants in the first year of life: a longitudinal study}

\begin{abstract}
This study identifies the primary socio-communicative abilities evidenced by infants in three points in their first year of life, and the different configurations in each age. Emphasis is given to the idea that understanding child socio-cognitive and communicative dimensions is essential to acquire a better understanding of the genesis of human development and language. Six mother-infant dyads participated in the study. Infants were observed in their homes for 40 minutes of free play at the ages of six, nine and 12 months of age. The results demonstrated that the socio-communicative abilities of the infants were reconfigured in each subsequent age, permitting us to identify, especially at the age of 12 months, a higher frequency of intentional communicative abilities. The empirical data obtained in this study contribute to a better understanding of infant social cognition in the first year of life, with a focus on the bidirectional nature of mother-child interaction.
\end{abstract}

Keywords: social cognition, intentionality, mother-child relations.

\section{Capacidades socio-comunicativas de bebés en el primer año de la vida: un estudio longitudinal}

\begin{abstract}
Resumen: Este artículo tiene por objetivo identificar las primeras habilidades sociales de comunicación manifestadas por bebés en tres momentos distintos del primer año de vida y sus diferentes configuraciones en cada edad. Se destaca la idea de que la comprensión infantil de la dimensión social cognitiva y comunicativa es fundamental para una comprensión más profunda de la génesis del desarrollo humano y del lenguaje. Participaran en el estudio seis grupos de madres e hijos, con edades de seis, nueve y doce meses, observados en sus hogares, en una situación de juego libre de 40 minutos para cada edad. Los resultados del análisis mostraron que las habilidades sociales de comunicación de los niños estudiados fueron reconfigurándose en cada edad de forma subsecuente, siendo a los 12 meses cuando se identifica una mayor frecuencia de actos comunicativos. Se considera que los datos empíricos obtenidos contribuyen a una mejor comprensión de las habilidades sociales de comunicación en el primer año de vida, enfatizándose el carácter bidireccional de las interacciones madre-hijo.
\end{abstract}

Palabras clave: cognición social, intencionalidad, relaciones madre-hijo.

Uma das principais realizações da infância ocorre quando o bebê começa a dar indícios de que está se comunicando com o mundo. Essa habilidade nos seres humanos tem sido amplamente pesquisada na psicologia do desenvolvimento e, especificamente, por estudiosos da linguagem. Partindo de perspectivas teóricas diferentes (Meltzoff \& Moore, 1998;

\footnotetext{
${ }^{1}$ Este texto foi revisado seguindo o Acordo Ortográfico da Língua Portuguesa (1990), em vigor a partir de $1^{\circ}$ de janeiro de 2009.

${ }^{2}$ Endereço para correspondência:

Fabíola de Sousa Braz Aquino. Rua Mario Batista Júnior, 75/ Apto. 301. CEP 58.043-130. João Pessoa-PB, Brasil. E-mail:

fabiolabrazaquino@gmail.com
}

Messinger \& Fogel, 1998; Papaeliou \& Tevarthen, 2006; Tomasello, 2003), discute-se de que forma já no primeiro ano de vida os bebês demonstram capacidades sociocomunicativas marcantes.

Esses estudos compartilham a ideia de que as evidências encontradas acerca de tais habilidades são indispensáveis para a compreensão da gênese do desenvolvimento humano (Bruner, 1980; Meltzoff, 1995; Trevarthen, 1979, 2004), o que redimensionou as concepções acerca da infância, ao destacar aspectos singulares da cognição social de bebês desde os primeiros meses de suas vidas. A cognição social infantil, como afirma Striano e Reid (2006), refere-se 
à habilidade para compreender outras pessoas (...) e inclui todas as habilidades perceptivas básicas que nos habilitam a discriminar pessoas de objetos e o complexo interjogo de pistas sociais como o contato visual, movimentos do corpo, tom de voz e expressões faciais auxiliando na interpretação dos comportamentos dos outros e na capacidade e funcionamento da comunicação simbólica (p. 471).

Pesquisas em torno desta temática (Carpenter, Nagell, \& Tomasello, 1998; Messinger \& Fogel, 1998; Moore, 1999; Rivero, 2003; Rochat, 2007; Striano \& Vaish, 2006) têm destacado a existência de um conjunto de habilidades nos bebês que, ao se desenvolverem, trazem para sua vida social um tipo de interação considerada crucial para os intercâmbios com os adultos, quais sejam: as habilidades sociocomunicativas intencionais. Os dados derivados dessas pesquisas têm demonstrado de que forma esses atos surgem nas interações entre os bebês e suas mães, os períodos nos quais emergem as habilidades comunicativas intencionais, e suas funções nas trocas comunicativas, demarcando as estreitas relações entre comunicação pré-linguística, intenção comunicativa e aquisição da linguagem.

Principalmente a partir da década de 1970, pesquisadores (Bateson, 1979; Brazelton, 1979; Bruner, 1975; Halliday, 1979; Trevarthen, 1979) têm estudado habilidades sociocomunicativas nos bebês desde um período bem inicial do seu desenvolvimento, defendendo a ideia de uma "predisposição" do neonato para interagir com seu ambiente. Bateson (1979), estudando interações entre mães e bebês, observou padrão de alternância entre ambos, com sentenças curtas de fala materna dirigidas ao bebê, e respostas deste último em forma de murmúrios que juntos produziam uma breve troca conjunta semelhante a uma conversa, definida pelo autor como "protoconversação".

Nesta linha de raciocínio, Trevarthen (1979) observou que nas primeiras interações estabelecidas entre a mãe e o bebê surge um "significado rudimentar" compartilhado por ambos, evidenciado em episódios face a face que incluem olhar, tocar e vocalizar, movimentos da face, língua, lábios, braços e mãos, e do corpo todo do bebê, em uma estrutura claramente alternada. Esses movimentos são dirigidos à mãe que os recebe e, simultaneamente, dirige ao bebê sons e gestos. Para este autor, os referidos atos podem ser considerados a base para interações em que se percebem ação e atenção compartilhadas. Posteriormente, Trevarthen e Aitken (2001) propuseram que a inteligência social do bebê é uma capacidade psicobiológica inerente ao organismo, um requisito necessário, mas não suficiente dada a importância da intervenção cultural para o desenvolvimento da criança.

Teóricos como Bates, Camaioni e Volterra (1975), Camaioni, Aureli, Bellagamba e Fogel (2003), Volterra, Caselli, Capirci e Pizzuto (2004) encontraram em seus estudos que entre nove e doze meses de idade, dava-se o início da comunicação intencional dos bebês, sendo marcada pela emergência de gestos dêiticos tais como apontar, mostrar, oferecer e dar; solicitações ritualizadas como bater palmas e ferramentas comunicativas como o uso de sons e vocalizações semelhantes a palavras para comunicar uma intenção. Para esses autores, após esse período, entre 12 e 15 meses, começa a ser usado pelos bebês um novo tipo de gesto chamado representacional ou simbólico que denota um referente específico que se mantém independente do contexto (por exemplo, a criança acena se despedindo de alguém ou coloca o telefone no ouvido). Acrescentam que há interação entre os gestos e a fala e uma continuidade entre as primeiras formas linguísticas pré-verbais e a subsequente linguagem formal, cuja ocorrência se dá em grande parte em um contexto de atenção conjunta.

Seguindo a perspectiva sociocognitivista, Bruner (1975, 1980) sustenta que a participação do adulto funciona como um sistema de suporte social, uma espécie de "andaime" para o desenvolvimento dos bebês e sua apreensão dos sistemas culturais e simbólicos. Na visão desse autor, a participação do adulto e as atividades conjuntamente compartilhadas são fundamentais para o desenvolvimento cognitivo e linguístico infantil. $\mathrm{O}$ referido autor acrescenta ao argumento da "predisposição inata para a comunicação", a ideia de que as interações sociais estabelecidas entre bebês e adultos têm papel decisivo no desenvolvimento infantil. Para ele, no final do primeiro ano de vida, as crianças começam a exibir comportamentos sociointerativos, tais como: atenção conjunta, referência social e atos protocomunicativos, como mostrar e apontar, indicadores de uma considerável compreensão social dos bebês acerca do contexto.

No conjunto de teorizações acerca das habilidades sociocomunicativas no primeiro ano de vida, ressaltam-se os estudos realizados por Tomasello (1995, 1999), para quem a característica fundamental e única da espécie humana é a habilidade dos bebês de se comportarem, já no final de seu primeiro ano de vida, como seres intencionais e comunicativos. Parte fundamental dessa comunicação e das interações iniciais é a capacidade de estabelecer o contato visual com o outro, o que possibilita o acesso a dados e pistas sociais dos parceiros acerca dos momentos de início e término da interação.

Numa perspectiva sociopragmática, Carpenter, Nagell e Tomasello (1998) propõem que a gênese da participação e apropriação, por parte das crianças, dos artefatos e das práticas culturais humanas advém da capacidade que a criança desenvolve de olhar para onde o adulto olha, usar o adulto como ponto de referência, agir sobre os objetos da maneira como eles fazem, e posteriormente direcionar intencionalmente a atenção do adulto para um objeto do contexto, usando gestos comunicativos, tais como apontar e olhar. Segundo esses autores, subjacente a essas trocas, está o fato de que os participantes compartilham a atenção sobre algo, sendo esse foco conjunto um elemento basilar das futuras aquisições.

Tomasello (2003) defende que a capacidade sociocognitiva fundamental que sustenta a cultura refere-se à tendência 
de cada ser humano de se identificar com outros seres humanos, habilidade que se relaciona com o desenvolvimento da intencionalidade da criança. Para ele, as interações sociais que ocorrem entre adultos e crianças possibilitam seu envolvimento em aprendizagens culturais tipicamente humanas. Além disso, propõe que as primeiras interações da criança com sua mãe criam uma forma nova de representação cognitiva, calcada na natureza intersubjetiva dos símbolos linguísticos humanos compartilhados socialmente.

Estudando a questão da comunicação intencional, Rivero (2003), propôs que as análises das trocas comunicativas adulto-bebê devem privilegiar a noção de comunicação como processo social e relacional. Para esta autora, a comunicação é um processo de trocas cognitivas ou linguísticas diretamente relacionado às ações e interações concretas, pois está imbricado nas trocas interpessoais que geram as representações mentais e as dotam de sentido. Desse ponto de vista, a comunicação intencional é concebida como um processo social expresso a partir de intenções que, a princípio, ocorrem por meio de atos não-verbais tais como os gestos, as expressões faciais, movimentos e posturas do corpo de parceiros de uma interação.

Ainda conforme Rivero (2003), a habilidade comunicativa intencional passa por um processo de desenvolvimento gradual e pode ser manifestada a partir de condutas que inicialmente aparecem isoladas no bebê, mas que, via processos interativos, vão se tornando cada vez mais complexas. Para esta autora, as experiências de interação com o adulto permitem ao bebê construir no final do primeiro ano de vida uma representação do adulto como alguém que atua com intenções conforme as metas apresentadas no contexto imediato da interação. $\mathrm{Na}$ análise apresentada pela referida autora percebe-se a relevância atribuída ao caráter relacional e aos processos interativos adulto-bebê na constituição da comunicação intencional.

Na perspectiva de Rochat (2007), a intencionalidade comunicativa pode ser explicada como “(...) a capacidade mental dos indivíduos para se referirem a um objeto, quer este objeto exista ou não" (p. 9). Para ele, a intencionalidade pode ser expressa por meio de ações intencionais que começam a ser evidenciadas aos dois meses de vida após o nascimento do bebê, tendo como mecanismo responsável por tal desenvolvimento, a maneira única e tipicamente humana de comunicação recíproca e intencional entre o bebê e seus progenitores. Para Rochat (2007), as trocas recíprocas, o espelhamento afetivo e a imitação mútua possibilitam à criança uma oportunidade única para estabelecer distinções entre o "eu" e a perspectiva do outro.

Concorda-se como Rivero (2003) e Rochat (2007), que a peça-chave para a explicação da intencionalidade comunicativa, encontra-se nas primeiras interações sociais. Para Rochat (2007), a reciprocidade presente nas interações sociais é um mecanismo que possibilita à criança tornar-se intencional por permitir a ela a dissociação de perspectivas entre o eu e o outro, sobre os objetos, as pessoas e sobre si mesma.
Em relação a essa temática, foi encontrada por Messinger e Fogel (1998) uma estreita relação entre idade e o aumento de diversos tipos de ações comunicativas; idade e o aumento na proporção do tempo em que as crianças coordenavam sua atenção entre um objeto e o parceiro; e ainda uma relação entre idade, aumento na vocalização de caráter comunicativo intencional e o número de vocalizações acompanhando os gestos infantis. Papaeliou, Minadakis e Cavouras (2002) investigaram aspectos da linguagem de bebês nos primeiros seis meses de vida, como os gestos e expressões faciais, que possuem um demarcador comunicativo. Para eles, essas manifestações prélinguísticas são recursos comunicativos que os bebês utilizam para enviar mensagens a suas mães por meio do choro, sorriso, e demonstrações de desconforto ou prazer, cujos padrões vocais e de entonação auxiliam na interpretação materna do comportamento dos bebês e identificam a qualidade da comunicação, suas funções e intenções comunicativas.

Pesquisadores como Yale, Messinger, Delgado e CoboLewis (2003) relataram que os bebês no primeiro ano de vida usam vocalizações, expressões faciais e a direção do olhar quando interagem com outros. Conforme esses autores, o rápido desenvolvimento das habilidades das crianças nos seus primeiros meses de vida dá-se para combinar ações de diferentes modalidades de comportamentos em padrões específicos, como por exemplo, vocalizações que podem iniciar e terminar com um sorriso. Tais padrões coordenados podem ter significados comunicativos específicos que mudam com a idade.

Além desses estudos, merece destaque aqueles que articulam o conceito de intersubjetividade, construção de significados e engajamentos iniciais mãe-bebê (Nogueira \& Seidl-de-Moura, 2007); os que investigam por meio de interações iniciais mãe-bebê, as matrizes constitutivas de habilidades socioculturais, identificando processos recípro$\cos$ de engajamento que se modificam com as novas aquisições infantis e mobilizam por parte do adulto ajuste em seus comportamentos (Seidl-de-Moura \& Ribas, 2000; Ribas \& Seidl-de-Moura, 1999). Considera-se pertinente mencionar ainda estudos nos quais são abordados, a partir da perspectiva histórico-relacional, o desenvolvimento percebido como processo de mudança no qual as relações interpessoais se constroem mutuamente (Lyra, 2006).

Diante do exposto, este artigo tem por objetivo apresentar dados referentes às habilidades sociocomunicativas de bebês no primeiro ano de vida, buscando identificar as principais habilidades sociocomunicativas evidenciadas pelos bebês nos três períodos evolutivos observados e suas diferentes configurações em cada idade.

\section{Método}

\section{Participantes}

Participaram deste estudo seis díades mãe-bebê nas idades de seis, nove e doze meses. As mães dos bebês eram casadas, moravam em suas próprias residências, tinham 
idade média de 27,7 anos e nível de instrução a partir do superior incompleto. Das mães participantes deste estudo, quatro eram primíparas e duas tinham um filho além do bebê que participou do estudo. Segundo relato delas, os bebês não apresentaram problemas de saúde e nasceram a termo (idade gestacional maior que 38 semanas).

\section{Instrumentos}

Para conhecer os comportamentos comunicativos intencionais dos bebês foram utilizados uma câmera de vídeo, cronômetro, lápis e papel. As díades foram observadas em suas residências, em situação de brincadeira livre. Secrist, Koeyer, Bell e Fogel (2002) afirmam que este tipo de contexto pode aumentar a probabilidade do surgimento de criatividade e novidade durante o evento, consideradas vitais para mudanças no desenvolvimento.

\section{Procedimentos}

\section{Coleta de dados}

O contato com cada díade participante do estudo foi feito a partir da indicação de colegas que conheciam mães e bebês que se enquadravam nos critérios adotados, quais sejam: díades mãe-bebê com as crianças na idade inicial de seis meses, sendo as mães casadas, residentes em seus próprios domicílios e com nível de instrução a partir do ensino médio completo. O primeiro contato com as mães foi feito por telefone e, uma vez concedida a permissão para a visita à casa da díade, foi realizado o primeiro contato pessoal. $\mathrm{Na}$ primeira visita a pesquisadora expôs os objetivos do estudo e solicitou o consentimento para a realização dos registros das interações com o uso do vídeo. Conforme disponibilidade da mãe, realizava nesse primeiro momento a primeira das duas sessões de observação. Às mães foram dadas duas instruções: que "brincassem com seus filhos da maneira como faziam usualmente". Durante as sessões de observação estiveram apenas presentes a pesquisadora, a mãe e o bebê.

As díades foram observadas duas vezes em cada mês, iniciando aos seis meses, depois aos nove meses e concluindo aos doze meses, perfazendo um total de cento e vinte minutos de observação. Em cada momento evolutivo as díades foram observadas durante 20 minutos dos quais dez foram transcritos literalmente para análise, sendo desconsiderados os cinco primeiros e os cinco últimos minutos. Buscou-se manter entre as duas sessões de cada recorte evolutivo o intervalo de, em média, quinze dias. As observações realizadas além deste intervalo ocorreram em função de particularidades das famílias das díades (viagens, consultas médicas) ou do bebê (dormindo, doente).

\section{Análise dos dados}

A análise dos dados derivados das interações entre mães e bebês nos três períodos estudados buscou demonstrar os fluxos interativos característicos nas díades mãe-bebê em cada período evolutivo observado. Privilegiou-se uma leitura minuciosa dos tipos de interações que ocorreram em cada episódio, na perspectiva de identificar as principais habilidades sociocomunicativas evidenciadas pelos bebês nos três períodos evolutivos observados e as possíveis modificações em cada idade subsequente das referidas habilidades.

O critério utilizado para analisar as habilidades comunicativas intencionais dos bebês foi a evidência comportamental, que indica se a criança tem intenção de comunicar algo em relação a um objeto ou ao parceiro (Rollins, 1999). Foi considerado um ato comunicativo o grupo de condutas nãoverbais e/ou verbais produzidas por um emissor com a intenção de influenciar o comportamento e/ou o estado mental do outro (Rivero, 2003). Exemplificam condutas intencionais nos bebês, comportamentos, vocalizações e formas de interação com as mães que abrangem: chorar; pegar objetos oferecidos pela mãe; estender os braços e tronco em direção a algo na presença do outro; dirigir a atenção do outro por meio do olhar (mesmo que não intencionalmente); mostrar um objeto para a mãe; dar objetos espontaneamente; oferecer um objeto ao parceiro deixando-o muito perto deste; e apontar (Papaeliou \& Trevarthen, 2006; Sarriá, 1991).

O processo de análise dos dados das interações videogravadas iniciou-se com as transcrições manuais de cada sessão; durante as transcrições cada cena ou episódio foi revisto segundo a segundo com o intuito de registrar de forma minuciosa as interações e atividades que surgiram a partir da situação de brincadeira livre e as formas de comunicação verbal e não-verbal de ambos os membros da díade. Na segunda etapa, as sessões de cada díade, já transcritas, foram revistas para identificar ações e vocalizações do bebê de natureza intencional e/ou não-intencional durante as interações. Por meio deste processo foi possível identificar e caracterizar as principais modalidades sociocomunicativas dos bebês em cada período subsequente analisado.

Após a transcrição dos dados videogravados, foi iniciada a etapa de levantamento na literatura das categorias de análise a serem adotadas, congruente com os dados das interações registradas e com os objetivos da pesquisa. A partir deste levantamento foi iniciado o processo de categorização dos episódios interativos, das habilidades sociocomunicativas das díades.

Para verificar a fidedignidade da codificação das habilidades sociocomunicativas dos bebês nos episódios interativos, $20 \%$ do material foi analisado por um segundo codificador para que fosse obtido o índice de concordância das categorias analisadas. A escolha dos protocolos para a análise do segundo codificador deu-se por sorteio, sendo codificados pelos mesmos seis protocolos divididos igualmente por grupo de idade e sexo dos bebês. $\mathrm{O}$ cálculo de fidedignidade adotado foi realizado através da fórmula $\mathrm{IF}=$ ( $\Sigma \mathrm{A} / \Sigma(\mathrm{A}+\mathrm{D}) \mathrm{X} 100)$. As porcentagens de concordância do segundo codificador foram comparadas com as do codificador original. A partir da comparação, obteve-se $87 \%$ de concordância das categorias. 


\section{Considerações éticas}

É importante mencionar que esta pesquisa foi submetida ao Comitê de Ética do Centro de Ciências da Saúde da Universidade Federal da Paraíba (UFPB), obtendo parecer favorável (protocolo $n^{\circ} 364 / 2006$ ). A participação de cada díade ocorreu e foi autorizada mediante assinatura do Termo de Consentimento e Livre Esclarecido.

\section{Resultados e Discussão}

Após a análise das interações por díade, foi realizada uma análise por grupo de idade para demonstrar as possíveis variações ocorridas em termos de atos sociocomunicativos dos bebês em interações com as mães. Para melhor visualização, os dados foram dispostos em figuras que serão apresentadas ao longo do texto.

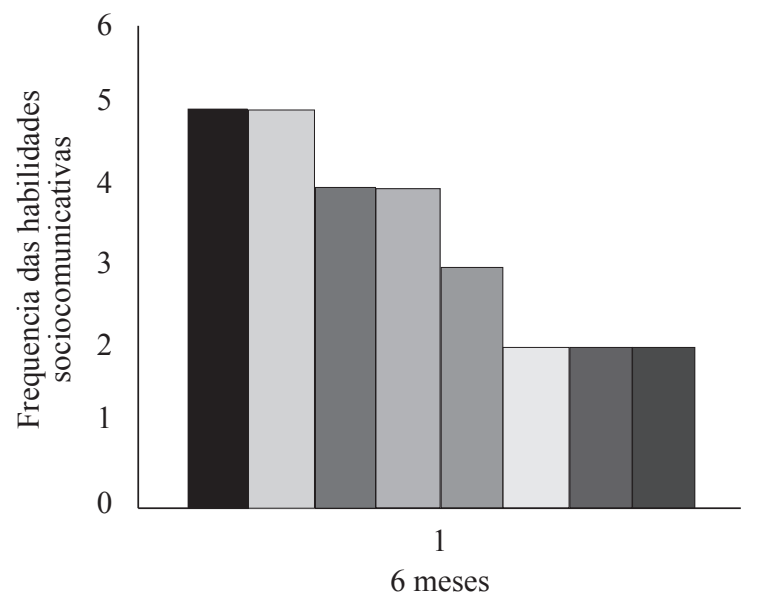

Na Figura 1 estão dispostos os principais comportamentos e atos sociocomunicativos dos bebês aos seis meses e suas respectivas frequências. No gráfico consta a frequência, nessa idade, de alguns dos comportamentos fundamentais para a aquisição da habilidade de atenção conjunta, tais como: acompanhar o deslocamento de brinquedo; olhar para objetos mostrados pela mãe; seguir o gesto de apontar da mãe para objetos próximos ao campo visual do bebê. Destaca-se nesse grupo a frequência de gestos dos bebês como: estender os braços para a mãe e para objetos; vocalizar enquanto olha e manuseia os brinquedos; e trechos em que o bebê sorri quando a mãe lhe mostra um brinquedo ou lhe dá voz. Esses comportamentos foram, em geral, bastante típicos entre os bebês desta idade, sendo considerados por pesquisadores como Rivero (2003) e Sarriá (1991) como intencionais, visto que para essas autoras a habilidade de comunicação intencional é percebida como uma habilidade construída desde as relações iniciais estabelecidas entre o bebê e o adulto.

Acompanha movimentos de brinquedos

$\square$ Estira os braços em direção a objetos

Olha para objeto mostrado pela mãe

$\square$ Vocaliza olhando e manuseando brinquedos

$\square$ Acompanha o apontar da mãe para objetos próximos

$\square$ Sorri com som que a mãe faz com um brinquedo

Sorri para brinquedo que a mãe lhe mostra

Estende os braços em direção à mãe

Figura 1. Frequência de ocorrência das habilidades sociocomunicativas dos bebês em interação com as mães, aos seis meses $(n=6)$.

Na visão de pesquisadores como Trevarthen (2004), após os três meses de vida, o bebê desenvolve o uso de seus sentidos e membros, buscando explorar e formar conceitos sobre os objetos, negociando seus propósitos, pois seu interesse a partir deste momento está mais focado nas mudanças do olhar de outra pessoa e na direção de sua atenção visual, habilidades que neste período representam importantes sinais de uma relação interpessoal.

Observa-se ainda, na Figura 1, o uso de gestos por parte dos bebês, tais como levantar ou dar os braços para o adulto; inclinar o corpo em direção a objetos; olhar fixamente para objetos e estender os braços em sua direção; e modificar suas expressões faciais em função da adoção, por parte das mães, de estilos ora positivos (face alegre, expressões faciais marcantes), ora coercitivos/neutros (quando as mães os repreendiam, usavam um tom de desaprovação ou quando olhavam para o bebê com uma face séria).
Deve-se pontuar que os bebês respondiam de forma instantânea às mudanças nas expressões faciais e verbais maternas, ao demarcado contorno prosódico utilizado pelas mães e a todo o repertório comportamental utilizado por elas para comunicar algo. Outra característica marcante nesse grupo foi a presença do choro que funcionou como principal "elemento comunicativo" frequentemente significado pelas mães, assim como o sorriso que, por outro lado, serviu como sinalizador para que as mães dessem continuidade a uma determinada atividade ou inferissem o interesse do bebê no que estava ocorrendo. Esses artifícios utilizados pelas mães durante suas interações com a criança são considerados fundamentais para mobilizar novas configurações de habilidades de comunicação dos bebês, aqui entendidas como um processo (Rivero, 2003). Sobre esse aspecto, retoma-se a ideia de Rochat (2007), segundo a qual a habilidade de comunicação intencional estaria atrelada às trocas 
recíprocas mãe-bebê, ao espelhamento afetivo e à imitação mútua que possibilitam à criança a construção da referida habilidade.

A Figura 2 apresenta os principais tipos de atos sociocomunicativos dos bebês aos nove meses, verifica-se que, em alguns dos bebês deste estudo, outras formas de comunicação não-verbal e de habilidades sociocomunicativas, tais como o olhar alternado; a imitação de gestos da mãe com objetos; ações espontâneas do bebê iniciando interações; o sorriso em antecipação a um gesto materno; respostas não- verbais corretas às solicitações; e diretivos da mãe em atividades de resolução de problemas tais como brinquedos de encaixe e de empilhar peças. Assinala-se que atos como responder de forma não-verbal às solicitações maternas; imitar o gesto da mãe com objeto e o sorriso em antecipação a um gesto materno; deram-se também em função das situações e atividades criadas pelas mães, o que evidencia o caráter bidirecional dessas trocas. Para pesquisadores como Tomasello (2003), esses comportamentos, de natureza triádica, seriam indicativos da habilidade comunicativa intencional.

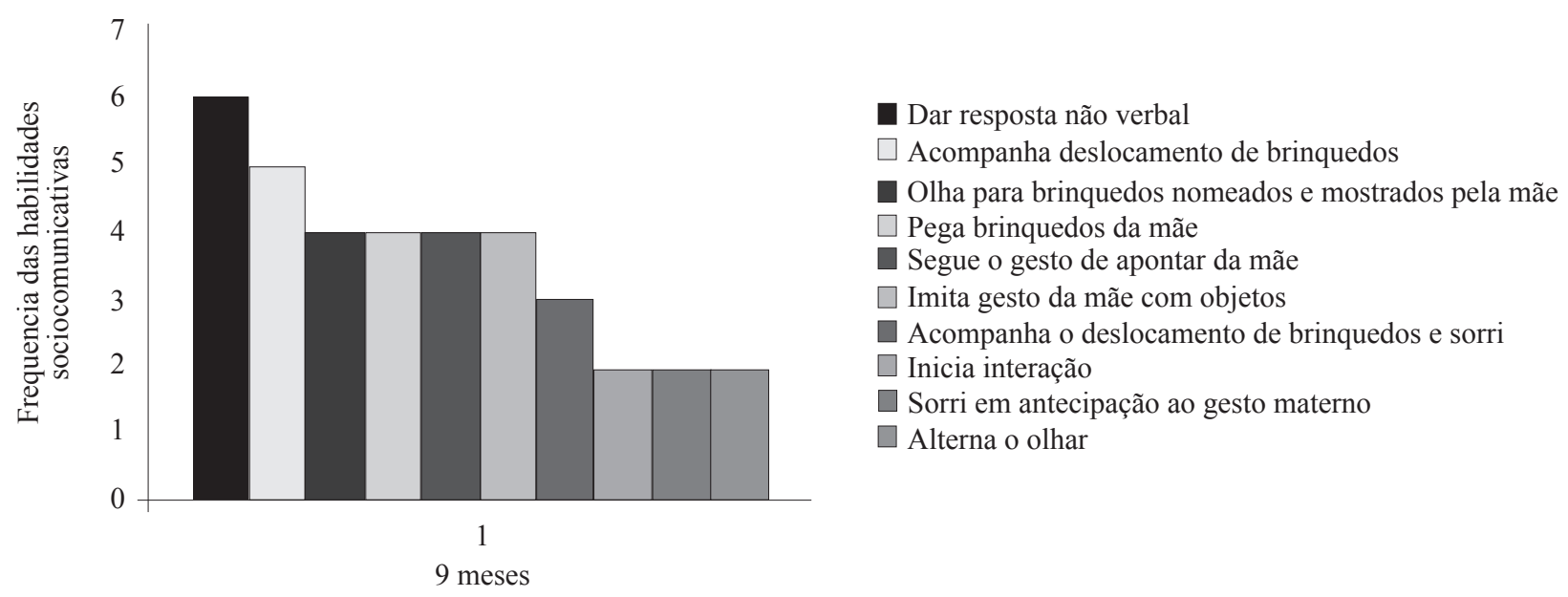

Figura 2. Frequência de ocorrência das habilidades sociocomunicativas dos bebês em interação com as mães, aos nove meses $(n=6)$.

Parte das habilidades acima descritas foram também apontadas por Bates, O'Connell e Shore (1987) cuja pesquisa relata que em torno dos nove meses de idade o bebê demonstra controle intencional sobre seus gestos, por meio da alternância do olhar (a criança olha para a mãe, depois para o objeto e novamente para a mãe); da correção de falhas na mensagem (se um gesto inicial falha em levar o adulto para uma determinada ação, a criança repetiria e/ou substituiria os gestos até que seu objetivo fosse alcançado); e da ritualização de gestos instrumentais (levanta os braços e vocaliza "mmmm").

A Figura 3 apresenta os principais comportamentos sociocomunicativos dos bebês aos 12 meses, dispondo as habilidades mais sofisticadas, possibilitadas também pela emergência da vocalização dos bebês coordenada com o uso de habilidades claramente intencionais em todos desta idade, quais sejam: olhar alternado; iniciar interação; usar convencionalmente objetos; ações meio-fim; seguir o gesto de apontar da mãe; imitar gestos da mãe com objetos; responder verbal e não-verbalmente a solicitações da mãe. Em cinco dos seis bebês estudados observaram-se comportamentos como emitir parte de palavra da mãe; envolver-se em tarefas de resolução de problemas; e apontar. A Figura 3 apresenta também atos dos bebês nessa idade que indicam a habilidade de participar da interação via jogo de papéis, tais como entregar brinquedo à mãe, quando solicitado, e vocalizar olhando para a mãe, sugerindo que os bebês compartilhavam os passos de cada atividade da interação. 


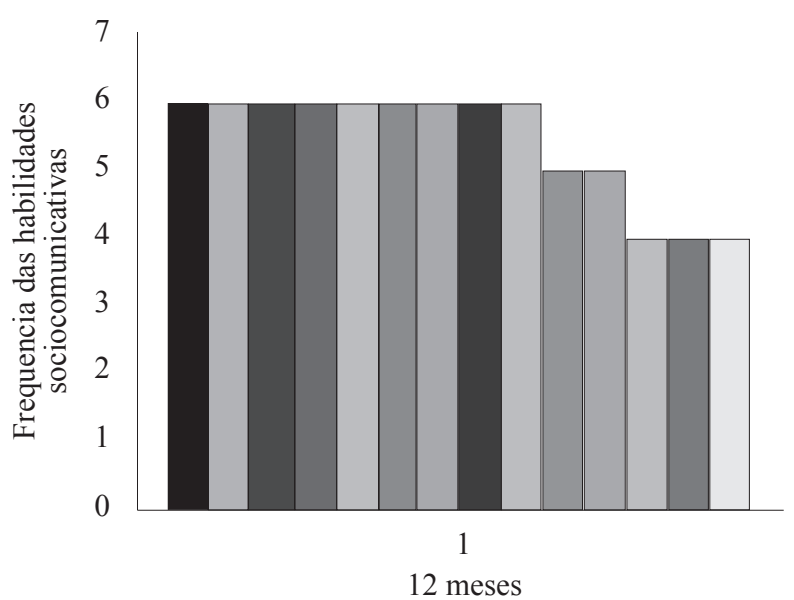

Alterna o olhar $\square$ Inicia interação

U Uso convencional de objeto e vocalizações

Ações meio-fim

$\square$ Segue gesto de apontar para objetos

$\square$ Imita gesto da mãe com objetos

$\square$ Dar resposta não verbal correta

Emite parte de palavra da mãe

$\square$ Envolve-se em tarefas de resolução de problemas

$\square$ Olha para a mãe e vocaliza

$\square$ Responde verbalmente completando ou enunciando parte de uma palavra $\square$ Aponta

Olha para um objeto e vocaliza

$\square$ Entrega brinquedo à mãe

12 meses

Figura 3. Frequência de ocorrência das habilidades sociocomunicativas dos bebês em interações com as mães, aos doze meses $(n=6)$.

Em relação às habilidades sociocomunicativas, os bebês nessa idade demonstraram compreender as intenções comunicativas e instruções maternas respondendo às solicitações das mães de forma correta tanto verbal quanto nãoverbalmente em situações de "resolução de problemas". Também evidenciaram durante as interações com as mães, modalidades comunicativas intencionais mais coordenadas e articuladas, tais como seguir o olhar e o ato de apontar da mãe para algo; agir evidenciando perceber as relações meio-fim de uma ação; e responder não-verbalmente às solicitações maternas. De acordo com Tomasello (1995, 2003), nesse momento do desenvolvimento, o bebê já teria adquirido a habilidade de compreensão das intenções da mãe. Além disso, evidenciaria a habilidade de dirigir sua atenção para aspectos específicos do contexto, tal como foi demonstrado pelo ato de pegar o brinquedo solicitado pela mãe; relacionar o objeto com seu referente linguístico; iniciar interações com a mãe; seguir o ato de olhar e de apontar da mãe para objetos; dar ou oferecer brinquedos vocalizando e olhando para a mãe; coordenar atos como apontar para objeto com alternância do olhar e estabelecer maiores recortes interativos de atenção conjunta dos bebês do presente estudo.

Conforme os dados apresentados e analisados, as interações observadas nos três períodos evolutivos permitiram identificar os diferentes meios utilizados pelos bebês para chamar a atenção das mães para eventos do contexto que merecem ser citadas. Aos seis meses, por exemplo, os bebês estenderam os dois braços e se inclinaram em direção às mães ou aos objetos, sendo esse gesto imediatamente significado e referenciado pelas mães. Já aos nove meses, o gesto de estender os dois braços em direção a objetos passou a ser menos utilizado pelo bebê, que, em vez disto, estendeu apenas um dos braços em direção a determinado objeto, alternando seu olhar entre a mãe e esse. Finalmente, aos doze meses, o bebê passou a utilizar o gesto de apontar via extensão do dedo indicador com os demais dedos curvados para trás, o que não havia sido observado nas idades anteriores. Neste caso, o bebê apontava para um objeto, alternando seu olhar entre a mãe e ele, usando ainda vocalizações que demarcaram a intenção de comunicar algo a ela. Entende-se que este percurso foi fundamental para a emergência do ato de apontar enquanto gesto comunicativo intencional.

Essas configurações em torno do gesto de apontar foram também encontradas por Franco (2007), que relata que, antes do final do primeiro ano de vida, o bebê expressa comportamentos que podem ser considerados precursores do designado apontar canônico, o qual é definido, segundo Franco (2007), pela extensão do braço e do dedo indicador com os demais dedos curvados. De acordo com os relatos desta autora, podem ser observados em bebês nas idades entre quatro e cinco meses, a extensão e o movimento de braços para alcançar ou agarrar objetos; já entre os oito e os dez meses de idade observa-se o uso do dedo indicador sobre objetos para explorar seus contornos e detalhes.

Cabe destacar a ideia de que o ato de apontar do bebê é um comportamento comunicativo antes mesmo da aquisição da fala e que sua emergência ocorre atrelada ao desenvolvimento cognitivo, emocional e ao controle motor. O gesto de apontar seria motivado, dentre outros fatores, pelo interesse do bebê em compartilhar de forma cooperativa aspectos do contexto (Franco, 2007; Liszkowski, 2005). Esse aspecto das interações foi aqui assinalado em virtude do papel que o gesto de apontar tem como um dos principais indicadores de que o bebê está dando evidência de uma habilidade comunicativa intencional.

Circunscritos a esse conjunto de ações do bebê e derivados de suas aquisições foram observados, conforme descrito nas Figuras 1, 2 e 3, atos coordenados como: olhar alternado entre um brinquedo e a mãe; seguir o gesto de apontar 
da mãe para objetos; imitar gestos das mães em relação a objetos; agir espontaneamente chamando a atenção da mãe com gestos e vocalizações; e ações sobre os brinquedos que demonstravam uma noção da relação meio-fim. Entende-se que tais habilidades, derivadas também de aquisições motoras, provocam importantes mudanças nas experiências dos bebês entre os nove e doze meses de vida. Em relação a este aspecto, Flom, Déak, Phill e Pick (2004) lembram que "o início da locomoção cria novas oportunidades para a interação social através de espaços amplos e aumenta a familiaridade com as trocas comunicativas não-verbais que incorporam a referência em distâncias maiores" (p. 193).

Com relação às aquisições motoras e suas repercussões no desenvolvimento infantil, Vygotsky (1932/1996) afirmou que a análise do comportamento social do bebê deve considerar as formas por meio das quais ele demonstra o domínio de seu próprio corpo, que inclui sua postura e movimentos. Em certas posições e estados, satisfeitas as suas necessidades, o bebê tem um excesso de energia que o deixa ativo: ele pode escutar atentamente e olhar ao seu redor com vivacidade. Mas se a postura cômoda e segura em que se encontra muda para outra que ele não domina, dirige toda a sua energia para superar tal incômodo. Este tipo de evento foi observado principalmente com bebês, aos seis meses, que utilizaram frequentemente seu corpo para comunicar à mãe desconforto ou satisfação diante de uma posição em que eram colocados. Além disso, os bebês nessa idade usaram de forma persistente comportamentos como olhar fixamente para objetos, estender os braços em direção aos brinquedos, movimentos do corpo que sugeriam a necessidade de se movimentar ou mudar de posição.

Nas observações que ocorreram aos nove e doze meses, a qualidade desses movimentos se alterou tornando mais evidentes os atos comunicativos de natureza intencional. A configuração de movimentos, de posturas corporais, gestos e expressões faciais tornou-se mais coordenada, e esse conjunto de aporte psicomotor caminhou lado a lado com as mudanças qualitativas nos formatos comunicativos observados durante as interações.

\section{Considerações finais}

O objetivo desta pesquisa foi expor dados relativos às habilidades sociocomunicativas de bebês no primeiro ano de vida, apresentando evidências empíricas obtidas por meio da observação e análise das interações mãe-bebê em três períodos evolutivos, algo ainda escasso nos estudos com bebês brasileiros. Os resultados obtidos revelam diferentes configurações dessas habilidades em cada idade estudada que, por seu turno, refletem habilidades sociocognitivas e comunicativas que se converteram gradativamente em formas de comunicação de natureza intencional. A análise permitiu verificar que as diferentes configurações dessas habilidades mobilizaram nas mães estilos interativos que evidenciaram a reciprocidade das interações.

Destaca-se, a partir deste estudo, a importância de pesquisas que analisem as interações mãe-bebê no primeiro ano de vida por meio da apresentação de dados empíricos referentes às habilidades sociocomunicativas iniciais, possibilitada por sua identificação nos três períodos evolutivos estudados. Sugere-se, a partir desta pesquisa, que estudos longitudinais sejam realizados acompanhando de forma contínua o surgimento das habilidades sociocomunicativas no primeiro ano de vida, o que pode favorecer uma melhor compreensão acerca da transição da habilidade comunicativa não intencional para a intencional. Ademais, esses estudos podem fornecer dados importantes para a detecção de prejuízos na comunicação e na linguagem, e subsidiar intervenções precoces no campo da cognição social infantil e da linguagem.

\section{Referências}

Bates, E., Camaioni, L., \& Volterra, V. (1975). The acquisition of performatives prior to speech. MerrillPalmer Quarterly, 21(3), 205-226.

Bates, E., O'Connell, B., \& Shore, C. (1987). Language and communication in infancy. In J. Osofsky (Ed.), Handbook of infant development (pp. 149-203). New York: Wiley.

Bateson, M. C. (1979). The epigenesis of conversational interaction: A personal account of research development. In M. Bullowa (Ed.), Before speech: The beginning of interpersonal communication (pp. 63-77). London: Cambridge University Press.

Brazelton, T. B. (1979). Evidence of communication during neonatal behavioral assessment. In M. Bullowa (Ed.), Before speech: The beginning of interpersonal communication (pp. 79-88). London: Cambridge University Press.

Bruner, J. S. (1975). From communication to language: A psychological perspective. Cognition, 3(3), 255-287.

Bruner, J. S. (1980). Early social interaction and language acquisition. In H. R. Schaffer (Ed.), Studies in motherinfant interaction (pp. 271-289). New York: Academic Press Inc.

Camaioni, L., Aureli, T., Bellagamba, F., \& Fogel, A. (2003). A longitudinal examination of the transition to symbolic communication in the second year of life. Infant and Child Development, 12(1), 1-26.

Carpenter, M., Nagell, K., \& Tomasello, M. (1998). Social cognition, joint attention, and communicative competence from 9 to 15 months of age. Monographs of the Society for Research in Child Development, 63(4), 1-175.

Flom, R., Déak, G. O., Phill, C. G., \& Pick, A. D. (2004). Nine-month-olds' shared visual attention as a function of gesture and object location. Infant Behavior \& Development, 27(2), 181-194. 
Franco, F. (2007). Infant pointing: Harlequin, Servant of two masters. In N. Eilan, C. Hoerl, T. MacCormack, \& J. Roessler (Eds.), Joint attention: Communication and other minds: Issues in philosophy and psychology (pp. 129-164). New York: Oxford.

Halliday, M. A. K. (1979). One child's protolanguage. In. M. Bullowa (Ed.), Before speech: The beginning of interpersonal communication (pp. 171-190). London: Cambridge University Press.

Liszkowski, U. (2005). Human twelve-months-olds point cooperatively to share interest with and helpfully provide information for a communicative partner. Gesture, 5(1/2), 135-154.

Lyra, M. C. D. P. (2006). O modelo EEA para a investigação da emergência e desenvolvimento da comunicação e do self: Bases conceituais e fundamentos teórico-metodológicos. Estudos de Psicologia (Natal), 11(1), 25-33.

Meltzoff, A. N., \& Moore, M. K. (1998). Object representation, identity, and the paradox of early permanence: Steps toward a new framework. Infant Behavior \& Development, 21(2), 201-235.

Meltzoff, A. N. (1995). Understanding the intentions of others: Re-enactment of intended acts by 18 -month-old children. Developmental Psychology, 3(5), 838-850.

Messinger, D. S., \& Fogel, A. (1998). Give and take: The development of conventional infant gestures. MerrilPalmer Quarterly, 44(4), 566-590.

Moore, C. (1999). Intentional relations and triadic interactions. In P. D. Zelazo, J. W. Astington, \& D. R. Olson (Eds.), Developing theories of intention: Social undertanding and self-control (pp. 43-61). Mahwah: Lawrence Erlbaum Associates.

Nogueira, S. E., \& Seidl-de-Moura, M. L. (2007). Intersubjetividade: Perspectivas teóricas e implicações para o desenvolvimento infantil inicial. Revista Brasileira de Crescimento e Desenvolvimento Humano, 17(2), 122-132.

Papaeliou, C. F., Minadakis, G., \& Cavouras, D. (2002). Acoustics patterns of infant vocalizations expressing emotions and communicative functions. Journal of Speech, Language and Hearing Research, 45(2), 311317.

Papaeliou, C. F., \& Trevarthen, C. (2006). Prelinguistic pitch patterns expressing communication and apprehension. Journal of Child Language, 33(1), 163-178.

Ribas, A. F. P., \& Seidl-de-Moura, M. L. (1999). Manifestações iniciais de trocas interativas mãe-bebê e suas transformações. Estudos de Psicologia (Natal), $4(2), 273-288$.

Rivero, M. (2003). Los inícios de la comunicación: La intencionalidad comunicativa y el significado como procesos graduales. Anuário de Psicologia, 34(3), 337-356.
Rochat, P. (2007). Intentional action arises from early reciprocal exchanges. Acta Psychologica, 124(1), 8-25.

Rollins, P. R. (1999). Early pragmatics accomplishments and vocabulary development in preschool children with autism. American Journal of Speech-Language Pathology, 8(2), 181-190.

Sarriá,E. (1991). Observación de la comunicación intencional preverbal: Um sistema de codificación basado em el concepto de categoria natural. Psicotema, 3(2), 359-380.

Secrist, C., Koeyer, I. De., \& Fogel, A. (2002). Combining digital video technology and narrative methods for understanding infant development [Versão eletrônica]. Forum: Qualitative social Research, 3(2). Recuperado em 20 outubro 2006, de http://www.qualitative-research. net/fqs-eng.ht

Seidl-de-Moura, M. L., \& Ribas, A. F. P. (2000). Desenvolvimento e contexto sociocultural: A gênese da atividade mediada nas interações iniciais mãe-bebê. Psicologia: Reflexão e Crítica, 13(2), 245-256.

Striano, T., \& Reid, V. M. (2006). Social cognition in the first year. Trend in Cognitive Sciences, 10(10), 471-476.

Striano, T., \& Vaish, A. (2006). Seven-to-9-month-old infants use facial expression to interpret others' actions. British Journal of Developmental Psychology, 24(4), 753-760.

Tomasello, M. (1995). Joint attention as social cognition. In C. Moore \& P. J. Dunham (Eds.), Joint attention: Its origins and role in development (pp. 60-83). Hillsdale: Lawrence Erlbaum Associates.

Tomasello, M. (1999). Having intentions, understanding intentions, and understanding communicative intentions. In P. D. Zelazo, J. W. Astington, \& D. R. Olson (Eds.), Developing theories of intention: Social undertanding and self-control (pp. 63-75). Mahwah: Lawrence Erlbaum Associates.

Tomasello, M. (2003). Origens culturais da aquisição do conhecimento humano (C. Berliner, Trad.). São Paulo: Martins Fontes.

Trevarthen, C. (1979). Communication and cooperation in early infancy: A description of primary intersubjectivity. In M. Bullowa (Ed.), Before speech: The beginning of interpersonal communication (pp. 321-347). London: Cambridge University Press.

Trevarthen, C. (2004). Learning about ourselves, from children: Why a growing human brain needs interesting companions. In C. Trevarthen (Ed.), Perception in action publications (pp. 1-36). Scotland: University of Edinburgh.

Trevarthen, C., \&Aitken, K. J. (2001). Infant intersubjectivity: Research, theory, and clinical applications. Journal of Child Psychology and Psychiatry, 42(1), 3-48. 
Volterra, V., Caselli, M. C., Capirci, O., \& Pizzuto, E. (2004). Gesture and the emergence and development of language. In M. Tomasello \& D. Slobin, (Eds.), Elizabeth Bates: A festschrift (pp. 3-40). Mahwah: Lawrence Erlbaum Associates.

Vygotsky, L. S. (1996). El primer año. In Obras escogidas: Psicología infantil. (L. Kuper, Trad., Tomo IV, pp. 275318.). Madrid: Visor (Original publicado em 1932)

Yale, M. E., Messinger, D. S., Delgado, C. F., \& CoboLewis, A. B. (2003). The temporal coordination of early infant communication. Developmental Psychology, $39(5), 815-824$.

Fabiola de Sousa Braz Aquino é Professora Doutora do Departamento de Psicologia da Universidade Federal da Paraíba.

Nádia Maria Ribeiro Salomão é Professora Doutora do Departamento de Psicologia da Universidade Federal da Paraíba.

Recebido: 08/02/2010

$1^{a}$ revisão: $24 / 10 / 2010$

Aceite final: 09/02/2011 